\title{
DNA methylation, imprinting and cancer
}

\author{
Christoph Plass ${ }^{*, 1}$ and Paul D Soloway ${ }^{*, 2}$
}

${ }^{1}$ Division of Human Cancer Genetics and the Comprehensive Cancer Center, The Ohio State University, Columbus, Ohio, OH 43210, USA; ${ }^{2}$ Department of Molecular and Cellular Biology, Roswell Park Cancer Institute, Buffalo, New York, NY 14263, USA

It is well known that a variety of genetic changes influence the development and progression of cancer. These changes may result from inherited or spontaneous mutations that are not corrected by repair mechanisms prior to DNA replication. It is increasingly clear that so called epigenetic effects that do not affect the primary sequence of the genome also play an important role in tumorigenesis. This was supported initially by observations that cancer genomes undergo changes in their methylation state and that control of parental allele-specific methylation and expression of imprinted loci is lost in several cancers. Many loci acquiring aberrant methylation in cancers have since been identified and shown to be silenced by DNA methylation. In many cases, this mechanism of silencing inactivates tumour suppressors as effectively as frank mutation and is one of the cancer-predisposing hits described in Knudson's two hit hypothesis. In contrast to mutations which are essentially irreversible, methylation changes are reversible, raising the possibility of developing therapeutics based on restoring the normal methylation state to cancer-associated genes. Development of such therapeutics will require identifying loci undergoing methylation changes in cancer, understanding how their methylation influences tumorigenesis and identifying the mechanisms regulating the methylation state of the genome. The purpose of this review is to summarise what is known about these issues.

European Journal of Human Genetics (2002) 10, 6-16. DOI: 10.1038/sj/ejhg/5200768

Keywords: DNA methylation; $\mathrm{CpG}$ island; cancer; genomic imprinting

\section{Regulation of DNA methylation in normal development}

\section{Introduction}

In the mammalian genome, cytosine residues may be methylated at the $5^{\prime}$ carbon. This occurs most commonly at 5'-CG-3' dinucleotides but cytosine methylation can be found at $5^{\prime}-\mathrm{CA}-3^{\prime}$ or $5^{\prime}-\mathrm{CT}-3^{\prime}$ residues. ${ }^{1}$ Since $5^{\prime}-\mathrm{CG}-3$ is

*Correspondence: Christoph Plass, PhD, The Ohio State University, Division of Human Cancer Genetics, Medical Research Facility 494A, 420 West 12th Ave., Columbus, Ohio 43210, USA. Tel: +614 2926505 ; Fax: +614 688 4761; E-mail: plass-1@medctr.osu.edu or Paul D Soloway, Dept. of Molecular and Cellular Biology, Roswell Park Cancer Institute, Elm and Carlton Streets, Buffalo, NY 14263, USA, Tel: +716 845 5843; Fax: +716 845 5908; E-mail: paul.soloway@roswellpark.org Received 27 September 2001; revised 5 December 2001; accepted 6 December 2001 palindromic, the cytosine on one or both DNA strands may be methylated (hemi-methylated and homo-methylated respectively). DNA methylation is an epigenetic modification that does not alter the primary sequence of DNA and is critical for normal development, gene expression patterns and genomic stability (see Table 1). DNA methylation patterns are dynamic - unmethylated sequences can become methylated and methyl groups can be lost. For example, differences in methylation patterns have been described between oocytes and generally more highly methylated sperm DNA; post-fertilisation development is characterised by waves of genome-wide demethylation in early stages and subsequent remethylation before implantation; CpGs within promoters of many genes on the inactive X-chromosome in female cells are methylated and may be part of the $\mathrm{X}$ inactivation mechanism; differentially methylated regions (DMRs) have been described for imprinted genes where the allele from one parent is methylated but the other is not (see below for more details). Of particular relevance to this review 


\begin{tabular}{|c|c|}
\hline Process & Consequence \\
\hline $\begin{array}{l}\text { Demethylation and remethylation } \\
\text { during embryonic development: } \\
\text { X-chromosome inactivation: } \\
\text { Genomic imprinting: }\end{array}$ & $\begin{array}{l}\text { - A wave of demethylation is followed by reestablishment of methylation patterns in early } \\
\text { embryogenesis and results in reprogramming of the genome. } \\
\text { - Silencing of genes on inactive X chromosome resulting in dosage compensation. } \\
\text { - Differentially methylated regions are regulatory sites ensuring parent-of-origin specific } \\
\text { expression of imprinted genes. }\end{array}$ \\
\hline Tissue specific methylation: & - Regulation of tissue specific expression. \\
\hline Age related methylation: & $\begin{array}{l}\text { - Hypermethylation of specific CpG islands in an age-dependent manner in colonic tissue } \\
\text { results in gene silencing. }\end{array}$ \\
\hline \multirow[t]{2}{*}{ Repeat methylation: } & $\begin{array}{l}\text { - Silencing of interspersed repetitive retrotransposons such as ALU or LINE1 elements. } \\
\text { - Hypothesized to protect from deleterious gene insertion events. } \\
\text { - Contributes to genomic stability by hypermethylation of heterochromatic satelite } \\
\text { repeat sequences. }\end{array}$ \\
\hline & Abnormal \\
\hline Process & Consequence \\
\hline Hypermethylation of CpG islands: & $\begin{array}{l}\text { - Inactivates tumour suppressor genes and other cancer related genes. } \\
\text { - Areas of frequent chromosomal breakage correlate with DNA hypermethylation. }\end{array}$ \\
\hline Hypomethylation: & $\begin{array}{l}\text { - Chromosomal instability caused by hypomethylation of normally methylated satellite } \\
\text { repeat sequences or other heterochromatic sequences. } \\
\text { - Oncogene activation due to point mutations in methylated CpG dinucleotides or } \\
\text { activation of normally silent genes. } \\
\text { - Gene deletions due to mitotic recombination or chromosomal loss. }\end{array}$ \\
\hline Coding region hypermethylation: & $\begin{array}{l}\text { - 5-methylcytosine is deaminated and results in a C-T point mutations leading to altered } \\
\text { amino acid sequence and or premature stop codons. }\end{array}$ \\
\hline $\begin{array}{l}\text { Methylation changes in differentially } \\
\text { methylated regions: }\end{array}$ & $\begin{array}{l}\text { - Dysregulation of imprinted genes resulting in either biallelic expression or loss } \\
\text { of expression in imprinted genes. }\end{array}$ \\
\hline
\end{tabular}

is the fact that perturbations in DNA methylation have been associated with abnormal developmental processes including cancer.

\section{Establishment of methylation patterns (DNMTs and their actions)}

Methylation is established by de novo methyltransferases (see Figure 1). Replication of homomethylated DNA produces hemimethylated DNA in which one strand of the DNA remains methylated and the newly synthesised is unmethylated. Hemimethylated DNA can become homomethylated by maintenance methyltransferases which place a methyl group at the 5'-CG-3 complimentary to a methylated 5'-CG-3. The first DNA methyltransferase identified, DNMT1, was shown to have both de novo methylation $^{2}$ as well as maintenance activity, although the de novo activity is much weaker than the maintenance activity. In cells lacking DNMT1 maintenance methylation is not abolished indicating other DNMTs have maintenance activity. ${ }^{3}$ Two more potent de novo methyltransferases have been identified: DNMT3A and DNMT3B. Neither is required for maintenance activity since ES cells deficient for either DNMT maintain the pre-existing methylation patterns. ${ }^{4}$ The importance of each of these enzymes for normal development has been demonstrated in mouse mutants that lack the individual genes. Mouse embryos homozygous for mutant alleles of Dnmt1, Dnmt3a or Dnmt3b die early in development either before birth (Dnmt1, Dnmt3b), or a few weeks after birth (Dnmt3a). These experiments dramatically revealed the importance of DNA methylation in normal development, but also identified individual target sequences for each of the enzymes. For example, DNMT3B is required for the methylation of centromeric minor satellite repeat sequences and both DNMT3A and DNMT3B are involved in methylation of C-type retroviral repeats, IAP repeats, major satellite DNA and the differentially methylated region in Igf2. Sequence specificity of DNMT3A and DNMT3B seen in in vivo experiments was not seen in in vitro assays indicating the requirement for additional factors that direct methyltransferase activity. ${ }^{5}$ Proteins with homology to the other DNMTs (DNMT2 and DNMT3L) and alternatively spliced forms of DNMT1 and DNMT3B with altered function have been reported, ${ }^{6,7}$ however their functions are not completely understood.

DNA demethylation may occur actively by an enzyme with demethylating activity, or passively by several rounds of replication in the absence of maintenance methyltransferase activity. There is evidence that both processes occur. Active demethylation occurs predominantly on the paternally transmitted chromosomes in zygotes while maternal chro- 


\section{Cis-acting regulatory factors}

Information about cis-acting regulation of DNA methylation has come from studies of the imprinted loci (see below). The reproducible, parent-of-origin-specific patterns of methylation detectable at those loci provide models for identifying DNA elements that determine whether or not the locus acquires methylation. The $I g f 2 r$ locus is methylated on the maternal allele which is also the expressed allele in mice. A $3 \mathrm{kbp}$ intronic element termed region 2 was shown in transgenic studies to contain the imprinting center needed for imprinted methylation and expression. ${ }^{12}$ Subsequent studies identified two sequences within region 2 that regulate maternal allele-specific methylation in the post-zygotic, pre-implantation embryo. One sequence termed the DNS provides a $\underline{\text { de }}$ novo methylation signal and is needed for methylation establishment of the maternal allele. A second sequence called the ADS provides an allele discrimination signal that protects the paternal allele from acquiring methylation directed by the DNS. A factor detectable in both androgenetic and gynogenetic ES cells can interact with the DNS while a factor detectable only in androgenetic ES cells interacts with the ADS. ${ }^{13}$ Presumably, the methylation patterns seen in later embryos and adults at the endogenous $I g f 2 r$ locus depend upon these cis-acting elements.

The Rasgrf1 locus is methylated on the paternal allele. Expression is also paternal allele-specific in neonatal brain. ${ }^{14}$ Deletion of a repeated sequence element (40 copies of a 41mer) $3^{\prime}$ of the differentially methylated domain prevented establishment of paternal allele methylation in the male germ line. Methylation patterns, once disrupted at the establishment stage, never became established in the soma. ${ }^{15}$ Interestingly, repeats and inverted repeats have been described as regulating local methylation in mouse cells ${ }^{16}$ and in plants. ${ }^{17}$

At the H19/Igf2 locus, a region $5^{\prime}$ to the $H 19$ gene is methylated on the paternal allele. Deletion of $2 \mathrm{kbp}$ of this region did not perturb establishment of methylation of the remaining differentially-methylated sequences, however, established methylation patterns were not efficiently maintained. ${ }^{18}$ This highlights potentially important differences between regulation of methylation establishment in the germ line and maintenance of established patterns in somatic tissue. A recent study identified Dnmt3L as a key player in the establishment of DMR methylation. Dnmt3L is expressed during gametogenesis at stages where genomic imprints are established. Mice lacking this gene do not establish methylation on the maternal allele in DMRs indicating the importance of DNMT3L for the imprinting process. ${ }^{19}$

Further clues about cis- and trans-acting factors regulating methylation in mammals may be provided by genetic screens in plants and fungi for modifiers of methylation-dependent processes. ${ }^{17,20-22}$ Results from these studies demonstrate conservation in plants of factors known to be involved in 
DNA methylation in mammals. It is likely that these systems will reveal important clues about how methylation control goes awry in human cancer.

\section{Methylation and transcription}

It is now well established that DNA methylation is involved in regulating gene transcription. This can occur by a variety of mechanisms. The interactions of several transcription factors whose binding sites contain CpG dinucleotides has been shown to be methylation-sensitive. ${ }^{23,24}$ However, methylated DNA more profoundly affects transcription by interacting with methyl-CpG-binding proteins and associated factors that alter chromatin structure.

The first two methyl-CpG-binding proteins (or protein complexes) to be identified were MeCP1 and MeCP2. ${ }^{25,26}$ MeCP2 is a single polypeptide with a methyl CpG binding domain (MBD) and a transcriptional repression domain (TRD). ${ }^{27}$ Interestingly, mutations in MeCP2 cause Rett syndrome, one of the leading causes of mental retardation and autistic behaviour. ${ }^{28}$ The $\mathrm{MBD}$ motif is found in four additional methyl-CpG-binding proteins (MBD1, 2, 3, and 4). ${ }^{29}$ One of these (MBD2) facilitates the binding of the multiprotein MeCP1 complex to methylated DNA. $^{30}$ How proteins with methyl-CpG-binding activities repress transcription is under active study. There is evidence for a variety of complex mechanisms. One key mechanism involves MBD-mediated recruitment to methylated DNA one of two co-repressor complexes, Sin3 and Mi-2/NuRD, which in turn recruit a core histone deacetylase complex consisting of HDAC1, HDAC2 and two $\mathrm{Rb}$ associated, histone-binding proteins, RbAP46 and RbAP48 ( ${ }^{31-33}$ reviewed in $\left.{ }^{34,35}\right)$. Additional co-repressor complexes exist, however, their role in silencing mechanisms that involve DNA methylation has not been demonstrated. HDACs remove acetyl groups from the lysine residues found at the N-termini of histone H3 and $\mathrm{H} 4$ (reviewed $\mathrm{in}^{36}$ ). Their removal results in an increase in the positive charge of the histones which is hypothesised to condense chromatin by enabling a tighter association between the histones and the negatively charged DNA. This may in turn silence transcription by limiting transcription factor binding. The Mi-2/NuRD co-repressor complex which recruits the HDAC core complex also includes factors that remodels chromatin by ATP-dependent mechanisms. ${ }^{37}$ These activities can reposition nucleosomes on DNA which may restrict interactions between the DNA and transcription factors.

This description is surely an over-simplification. First, the chromatin remodelling and histone deacetylation activities are interdependent. It has been observed that the remodelling activity of $\mathrm{Mi}-2 / \mathrm{NuRD}$ is required for $\mathrm{Mi}-2 / \mathrm{NuRD}$ dependent deacetylation by the core HDAC complex $\left({ }^{37}\right.$ reviewed $\mathrm{in}^{38}$ ). Second, DNA methylation may require HDAC activity or components of the chromatin remodelling apparatus. In support of this are the observations that treatment of Neurospora crassa with the HDAC inhibitor trichostatin A (TSA) can lead to loss of DNA methylation, ${ }^{39}$ mutations in ATRX, a member of the SWI/SNF chromatin remodelling family, causes regional hyper- and hypomethylation in the genome ${ }^{34}$ and DNMTs form complexes with HDACs. $5,10,40,41$ Third, adding to the varied interrelationships among silencing mechanisms is the fact that HDACs recruit sequence-specific transcriptional repressors that contribute to silencing, so transcriptional repression by HDACs may not rely solely upon DNA methylation to identify loci to be repressed. Similarly, acetylation- and methylation-mediated repression may function independently. This is supported by studies using the demethylating agent 5-aza-dC and the HDAC inhibitor, TSA. In vitro studies show that for several repressed loci, both drugs were needed for maximum de-repression - one alone would not suffice. $^{30}$ Taken together, these observations highlight the complex interactions among DNA methylation, histone acetylation, chromatin remodelling and sequence-specific silencing mechanisms that collectively attenuate gene expression.

While methylation is commonly associated with transcriptional repression, there are at least two cases at imprinted loci where methylation results in transcriptional activation. At the imprinted loci H19/Igf2 and Rasgrf1, the differentially methylated domains possess enhancer-blocking activity that restricts enhancer to promoter interactions, preventing promoter activation $\left({ }^{42,43}\right.$ and Yoon et al. unpublished). Binding of the factor CTCF, which is required for the blocking activity, is methylation-sensitive (Figure 2). Methylation of the CTCF site blocks binding and restores enhancer to promoter interactions which activates expression of $I g f 2$ or Rasgrf1. Biallelic lgf2 expression seen in cancers may involve interference with this mechanism. The mechanism by which CTCF prevents transcription may involve the binding of SIN3A and associated HDACs to an internal $11 \mathrm{Zn}$ fingercontaining region of CTCF and possibly additional corepressors to the C-terminus. ${ }^{44}$

There may be additional mechanisms by which DNA methylation affects transcription. In vitro studies have shown that methylation at cytosine residues can cause several changes in DNA structure (reviewed in ${ }^{45}$ ). Methylation has been shown to increase the helical pitch of DNA, ${ }^{46}$ alter the rate constants for cruciform formation, lower the free energy of Z-DNA formation, and promote helix unwinding at B/ZDNA junctions. ${ }^{47}$ If these DNA structural changes occur in vivo and affect binding of transcription-regulating factors is not known.

Regardless of the mechanisms by which methylation regulates gene expression, a large number of genes respond to methylation levels. In studies using fibroblast cells in which a Dnmt1 deletion was induced, up to $10 \%$ of over 5000 genes examined underwent significant changes in expression upon induction of the deletion. ${ }^{48}$ 
NORMAL
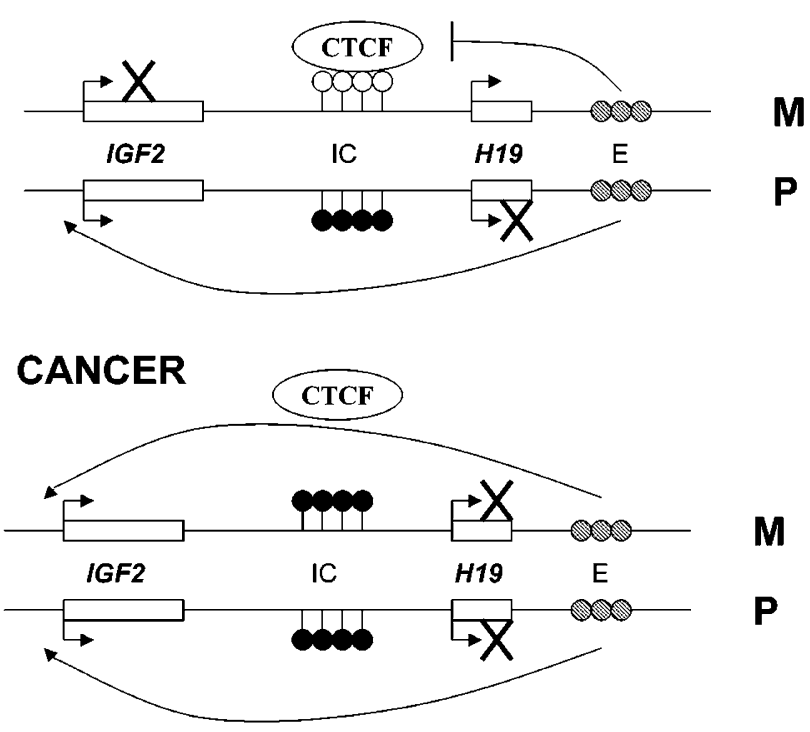

Figure 2 Methylation and the regulation of imprinted IGF2/ H19. IGF2 and $H 19$ are two imprinted genes located within the same chromosomal domain. IGF2 is normally transcribed from the paternal $(P)$ allele while $H 19$ is transcribed from the maternal (M). Imprinted expression in both genes is regulated by an imprinting center (IC) in which the maternal allele is unmethylated (open circles) and the paternal is methylated (filled circles). The imprinting center contains CTCF binding sites to which CTCF binds only if they are unmethylated. Binding of CTCF blocks the activity of the enhancer element (E) located downstream of $\mathrm{H} 19$ and restricts activity to $\mathrm{H} 19$ expression. Methylation of the CTCF binding sites prevents the binding of CTCF and allows the enhancer to activate IGF2. Biallelic expression of the CTCF binding sites in cancer results in IGF2 overexpression.

\section{Compartmentalisation of the genome by DNA methylation patterns}

The human genome is divided into several functionally different compartments with different base composition. Compartments include gene rich or gene poor regions, intergenic sequences, interspersed repetitive elements, and middle repetitive sequences such as the centromeric repeats. Further compartmentalisation comes through epigenetic modifications including different densities of chromatin condensation and DNA methylation patterns. CpG dinucleotides, the major target sequences for DNA methylation, are underrepresented in the genome compared to other dinucleotides. However, some GC-rich sequence stretches contain a higher frequency of $\mathrm{CG}$ dinucleotides. For example, $\mathrm{CpG}$ islands are GC-rich sequences between 0.2 and $2 \mathrm{~kb}$ in size and contain a higher than expected number of $\mathrm{CpG}$ dinucleotides $(\mathrm{CpG}$ to $\mathrm{GpC}$ ratio>0.6) and have a GC-content of more than $50 \%$ (reviewed $\mathrm{in}^{49}$ ). The majority of $\mathrm{CpG}$ islands are found in the promoter regions of genes. The majority of all CG dinucleotides in the genome are found repetitive elements such as rDNA, satellite sequences and centromeric repeats, and are usually unmethylated.

\section{Genomic imprinting and the involvement of DNA methylation}

The importance of specific DNA methylation patterns for developmentally appropriate gene expression is most clearly demonstrated for the imprinted loci. Normally, genes are expressed from both the maternal and the paternal alleles. At the imprinted loci, only the maternal or the paternal allele is expressed (for reviews see: ${ }^{50-53}$ ). Over 50 imprinted loci have been found in mammals (see http://cancer.otago.ac.nz/IGC/ Web/home.html and http://www3.ncbi.nlm.nih.gov/Omim/ search term 'imprint'). This restriction may be limited to specific tissues or times during development. The methylation status of the DNA surrounding an imprinted locus also displays a pattern that is unique to each allele. The locations of the differentially methylated domains or regions (DMDs or DMRs) are variable and the expressed allele may show both hypo- and/or hypermethylated domains ( ${ }^{15,54,55}$ reviewed in $^{56}$ ). These parental allele-specific methylation patterns may be established in primordial germ cells and are detectable in gametes, alternatively, they may appear in the zygote after fertilisation. Evidence indicates that the allele-specific patterns of methylation are what direct allele-specific expression. ${ }^{15,57}$ In the case of the H19/Igf2 and Rasgrf1 loci, the DMRs have enhancer blocking activity and bind CTCF in a methylation-sensitive manner ${ }^{42,43,58}$ (and Yoon unpublished result). As described earlier, CTCF bound to an unmethylated DMR represses enhancer to promoter interactions needed for Igf2 and Rasgrf1 expression and this block is relieved allowing expression when the DMRs are methylated and CTCF binding is prevented.

Other allele-specific phenomena can be observed at imprinted loci. These include differences in the timing of replication $^{59}$ and chromatin structure ${ }^{55,60,61}$ of the two parental alleles. These results reveal that whatever the mechanism of genomic imprinting, it influences several DNA-based phenomena and not just gene transcription.

\section{Methylation changes in cancer}

For many years, genetic changes that alter primary DNA sequence were thought to be the mechanism by which critical gene activities were lost in cancer. While these largely irreversible mutations are very common in cancer, it is now well established that DNA methylation plays a significant role in loss of gene function (reviewed in $^{62,63}$ ). Either homozygous methylation or methylation in combination with one of the genetic alterations has been described for multiple tumour suppressor genes and candidate cancer genes. Methylation can provide one of the hits postulated in 
Knudson's two hit hypothesis to inactivate tumour suppressor genes. Hypermethylation events in usually unmethylated CpG islands are found in a large number of cancer genes. Hypo- and hypermethylation events are found in the same tumour samples (reviewed $i^{64}$ ) indicating a defect in the regulatory mechanisms that participate in the establishment and maintenance of methylation patterns.

\section{Global hypomethylation in human malignancies}

Methylation changes in human malignancies were first reported almost 20 years ago. ${ }^{65}$ Studies by Ehrich $^{65}$ and Gama-Sosa, ${ }^{66}$ using HPLC to determine the 5 '-methylcytosine content in genomic DNAs, demonstrated a reduction of the overall amount of $5^{\prime}$-methylcytosine relative to normal tissues. Subsequent studies demonstrated a positive correlation between the degree of hypomethylation and the increasing malignancy grade or a correlation ${ }^{66-68}$ between tumour size and histological grade suggesting that hypomethylation may be a useful biomarker with prognostic significance. ${ }^{69}$ While global assays show that genome-wide levels of methylation decrease in many tumours, they do not provide information on where the hypomethylation occurs.

\section{Hypermethylation in cancer}

While global hypomethylation is detectable in the cancer genome, regions of hypermethylation are commonly found. Locus-specific methylation changes were initially studied using methylation sensitive restriction enzymes to digest genomic DNAs. A major breakthrough was made with the finding that sodium bisulphite treatment converts unmethylated cytosines to uracil whereas methylated cytosines remain unmodified. ${ }^{70}$ This treatment generates different sequences based on the methylation status of a gene. Subsequent PCR reactions using bisulphite-treated DNA can be performed to detect specifically the methylated sequences (MsPCR, Ms SNuPE). ${ }^{71,72}$ Alternatively, PCR products can be cloned and sequenced to identify methylated regions. A major emphasis in the past was the investigation of promoter methylation in known tumour suppressor genes. The list of genes that are found to be inactivated by DNA methylation events is growing rapidly and includes genes involved in apoptosis, angiogenesis, cell-cycle, differentiation, DNA repair, metastasis, signal transduction and transcription. Defects in a number of these genes have been identified as the underlying cause of familial cancer syndromes (reviewed in $\left.^{64}\right)$.

The effect of DNA methylation on transcription in cancer cell lines show that hypermethylation most commonly causes gene silencing. Treatment of these cell lines with $5^{\prime}-$ aza-2'-deoxycytidine results in demethylation of previously methylated sequences and subsequent activation of the gene under investigation.

\section{CpG island hypermethylation}

More recently, two methods were introduced that allow scanning for $\mathrm{CpG}$ island hypermethylation in tumour samples. Differential methylation hybridisation (DMH) is an array based approach in which CpG island sequences are spotted in high density onto nylon membranes. ${ }^{73}$ These arrays are subsequently hybridised with pools of PCR products derived from $\mathrm{CpG}$ islands that were amplified from genomic DNAs following BstUI digest. Bst UI is a methylation sensitive restriction enzyme and its recognition sequence is frequently located in CpG island sequences. PCR products are only amplified when the target sequence is methylated and thus undigested. Array profiles from normal and tumour tissue can be compared and methylated sequences are visualised by stronger signal intensities in the tumour profile compared to the normal tissue profile. This technique was used to study methylation in breast cancer and it was shown that overall levels of $\mathrm{CpG}$ island methylation correlate with histological grades. Poorly differentiated tumours appeared to show more hypermethylated CpG island sequences than moderately and well differentiated tumours. ${ }^{74}$

Restriction Landmark Genomic Scanning (RLGS), a twodimensional gel-electrophoretic technique, allows the assessment of methylation patterns in up to $2000 \mathrm{CpG}$ islands per gel by using rare-cutting, methylation sensitive restriction enzymes (e.g. NotI or $A s c I)^{75}$. RLGS profiles display unmethylated CpG islands, whereas methylated CpG islands are not displayed. Aberrant methylation in primary tumours or cancer cell lines is identified by comparing tumour RLGS profiles to profiles from matching normal DNAs. Loci aberrantly methylated in tumours are easily cloned using arrayed boundary libraries and subsequent database searches allow to link the methylation events to genes or ESTs.

Genome-wide scans for methylation changes in CpG islands showed that the frequencies of methylation are different between tumour types. ${ }^{75}$ Breast, head and neck and testicular tumours showed either no or relatively low frequencies $(<1 \%)$ of methylated $\mathrm{CpG}$ islands. Other malignancies including acute myeloid leukemias, colon cancer and brain tumours showed an overall much higher frequency of methylation ranging up to $10 \%$ of all $\mathrm{CpG}$ islands tested. Patterns of methylation were not random, suggesting the existence of mechanisms that either allow the preferential methylation of certain CpG islands or a selective pressure that favours the growth of cells with specifically methylated CpG island sequences. The non-random nature of CpG island methylation patterns was underlined by the finding of several hypermethylated CpG islands in the major breakpoint cluster region for medulloblastomas on chromosome $17 \mathrm{p} 11.2$, suggesting a possible link between chromosomal instability in this region and hypermethylation events. ${ }^{76}$ Acute myeloid leukaemias showed a prevalence of hypermethylated CpG islands on chromosome 11, again supporting the finding that methylation patterns are not random. ${ }^{77}$ Careful inspection of the methylated target 
sequences allowed the identification of sequences that were methylated in several different tumour types and others that were methylated in a tumour-type specific manner. This finding is in line with reports by other groups that have found BRCA1 promoter methylation only in breast and ovarian cancers, VHL promoter methylation only in clear cell renal carcinomas and hemangioblastomas, while other tumour suppressor genes including p16, DAPK, MGMT, have been found methylated in multiple tumour types. ${ }^{64}$

\section{Methylated genes}

Both strategies, the gene-by-gene approach as well as the genome scanning approach, provided long lists of methylation targets. ${ }^{64,77-79}$ The significance of tumour suppressor gene inactivation in tumour progression has been already established. However, this is not the case for the genes identified in the genome scans for aberrant methylation. Genome scans may identify candidate tumour suppressor genes and genes for which no tumour suppressor function has been established. Several current examples should be highlighted. First, RLGS was used to scan hepatocellular carcinomas and identified several RLGS sequences that were methylated in the tumour samples. ${ }^{80}$ Cloning of one of these loci (spot 7) identified the promoter region of suppressor of cytokine signalling (SOCS1). ${ }^{81}$ SOCS1 is a member of the JAK/ STAT pathway where by binding of SOCS1 to JAK2 phosphorylation is inhibited. Silencing of SOCS1 by promoter methylation results in constitutive activation of the JAK/ STAT pathway and subsequent transactivation of target genes. The second example is bone morphogenic protein $3 \mathrm{~B}(B M P 3 B)$, identified in a screen for aberrant methylation in non-small cell lung cancers. ${ }^{79} B M P 3 B$ is a member of the transforming growth factor- $\beta$ (TGF $\beta$ ) superfamily, a group of secreted polypeptides that regulate a diverse spectrum of developmental processes. Members of this superfamily signal through Ser/Thr kinase receptor which subsequently propagate signals to the SMAD pathway. Methylation of the $B M P 3 B$ promoter was shown to correlate with gene silencing and could be reactivated in lung cancer cell lines by $5^{\prime}$-aza- 2 deoxycytidine. The effects of $B M P 3 B$ silencing for tumour progression need to be demonstrated, ${ }^{79}$ however, $B M P 3 B$ is located on chromosome 10q11, an area that shows loss of heterozygousity in lung cancer.

RAS effector homologue (RASSF1), a novel lung cancer tumour suppressor candidate gene, is located in a commonly deleted region of chromosome 3p. RASSF1A, the major transcript of this gene, is also silenced by DNA methylation in lung tumours. ${ }^{82}$ Subsequent reports have also demonstrated the silencing of RASSF1A by promoter methylation in several other cancer types. ${ }^{83,84}$ Re-expression of RASSF $1 A$ in lung cancer cell lines resulted in reduced numbers of colonies in colony formation assays, suppressed the anchorage independent growth and most importantly inhibited the formation of tumours in nude mice. ${ }^{82}$

\section{Methylation profiles and clinical diagnostics}

Genome scans such as RLGS allow the correlation of thousands of methylation events to clinical data. Frühwald et al. identified eight sequences in an RLGS scan that showed statistical significant correlation with survival of medulloblastoma patients. ${ }^{85}$ Surprisingly, one of these methylation events correlated with improved outcome. RLGS analysis in AML patients identified a sequence within the WIT1 gene that was methylated at a higher frequency in relapsed AML as compared to diagnostic samples thus correlating with a chemoresistant phenotype. ${ }^{86}$

\section{Dysregulation of genomic imprinting in cancer}

In addition to silencing known and candidate tumour suppressors, aberrant DNA methylation affects expression of imprinted genes. Loss of imprinting (LOI) of IGF2 and the tightly-linked $H 19$ locus has been associated with tumorigenesis in a variety of patients. In Wilms' tumour, imprinted expression of IGF2 is commonly relaxed resulting in maternal allele expression. ${ }^{87,88}$ This is associated with increased methylation and reduced expression from the maternal copy of the tightly linked $H 19$ locus. ${ }^{89-91}$ Similar patterns of LOI for either or both of these loci have been seen in patients with hepatoblastoma, ${ }^{92}$ uterine leiomyosarcomata, ${ }^{93}$ cervical carcinoma, ${ }^{94}$ renal cell carcinoma, ${ }^{95}$ rhadbomyosarcoma, ${ }^{96,97}$ gliomas $^{98}$ and colorectal cancer. ${ }^{99,100}$ It is not known if LOI of IGF2 or other imprinted loci is a cause or a consequence of neoplastic transformation, however, the importance of IGF2 in human cancer is supported by the observation that patients with Beckwith-Wiedemann Syndrome (BWS) express both IGF2 alleles and are predisposed to several cancers. ${ }^{101-103}$

The mechanisms and methylation events underlying the LOI at H19 and IGF2 vary from tumour to tumour, however, maternal allele methylation is commonly acquired at sequences that include the $H 19$ promoter and IGF2 enhancer blocker ${ }^{104,105}$ which can simultaneously silence $H 19$ and activate IGF2 on the maternal chromosome ${ }^{42}$ (see Figure 2).

Imprinted loci other than H19/IGF2 have also been implicated in cancer. In neuroblastomas without $N-M Y C$ amplification, maternal-specific deletions of $1 \mathrm{p} 36$ have been reported. ${ }^{106}$ This region was later shown to contain the $p 73$ tumor suppressor, a p53 homologue which is maternallyexpressed. ${ }^{107}$ Silencing of the active maternal allele by methylation has been observed in acute leukaemia and Burkitt's lymphoma ${ }^{108}$ but it is possible that methylationindependent means of silencing occur in other cancers. ${ }^{109}$ p57KIP2, a cyclin dependent kinase inhibitor, is expressed primarily from the maternal allele. ${ }^{110}$ In lung cancers with 11 p15 deletions, the maternal allele is predominantly deleted. ${ }^{111}$ In Wilms' tumours, it is substantially silenced, ${ }^{112}$ however, it is not clear if this results from aberrant methylation. NOEY2/ARHI is a maternally-expressed tumour suppressor commonly found to be silenced by gene deletion in breast and ovarian cancers. The methylation status of 
intact alleles from tumours is not known. ${ }^{113}$ In hepatocellular carcinomas, multiple imprinted loci within the $11 \mathrm{p} 15$ region including $C D K N 1 C, S L C 22 A 1 L$, and $I G F 2$ genes were aberrantly silenced. ${ }^{114}$

\section{Causes of aberrant methylation}

Little is known about the mechanisms regulating DNA methylation in normal development and less is known about how these mechanisms go awry in cancer. Many correlative studies revealed increased levels of DNMTs in some cancer tissues or cells (reviewed $\mathrm{in}^{115}$ ), however, this was not universal. ${ }^{116}$ Furthermore, even when the correlation held, over expression of DNMTs alone was not sufficient for altered methylation patterns. ${ }^{117}$ Experimental models have supported the importance of DNMT expression levels in cancer development. In mice of strains susceptible to tumour formation, increased levels of Dnmt1 and methylated DNA were found in lungs from carcinogen-treated animals when compared to mice of resistant strains. However, in the strains used, there were many other strain-specific differences beyond Dnmt1 expression levels. ${ }^{118}$ In more easily controlled studies using Min mice which are predisposed to develop intestinal tumors, experimental reduction in Dnmt1 levels reduced tumour incidence. ${ }^{119}$ This is consistent with earlier observations that Dnmt1 has transforming activity in vitro. ${ }^{120}$

Regardless of the levels of DNMT protein, regulation of DNMT activity may be lost in cancer cells or precancerous lesions. This may be through changes in DNMT-associated factors that may regulate activity or subcellular localization. HDAC2, DMAP1 and TSG101 ${ }^{40}$ and two MBDs (MBD2 and MBD3 $)^{11}$ have all been shown to interact with DNMT1 and a histone methyltransferase is important to DNA methylation in Neurospora. ${ }^{9}$ If any of these are important for regulating DNMT activity in mammals and whether interfering with such regulation contributes to aberrant DNA methylation in cancer is not known.

\section{Perspectives}

As DNA methylation is important in the regulation of gene expression one could argue that the identification of aberrant methylation patterns could serve as a biomarker with predictive values for future progression or for the response to treatment. Several groups have been interested in these approaches. In a recent study by Esteller et al. the authors describe promoter methylation in the DNA repair gene O6methyl-guanine-DNA methyltransferase (MGMT). ${ }^{121}$ MGMT repairs alkylated sites in the DNA that otherwise would form cross-links between adjacent DNA strands. Alkylation of the DNA is the underlying principle of chemo-therapeutics such as carmustine that kill tumour cells and are used to treat patients with gliomas. Silencing of MGMT by promoter methylation was shown to correlate with the responsiveness of the gliomas to the treatment with alkylating agents. A different approach was used by Palisamo et al. in lung cancers where highly sensitive MS-PCR reactions were used to detect p16 and MGMT promoter methylation in sputum of patients up to three years prior to clinical diagnosis). ${ }^{122}$ This strategy offers the intriguing possibility of a population based screening for the detection of lung cancer. The identification of a powerful biomarker does not require the knowledge of the effect of DNA methylation on gene transcription. Several studies have identified methylated target sequences with statistically significant values.

The past years have moved the field of DNA methylation to a new level and improved our knowledge of targets affected by aberrant methylation in the cancer genome and how these changes lead to altered gene expression. Using model systems and selected genes, especially imprinted genes, it became possible to design studies that helped to explain the underlying mechanisms that regulate methylation changes. Future work will focus on several unanswered questions to determine how sequences become targets for aberrant methylation in cancer, to determine the regulatory mechanisms that malfunction in this disease and to determine the functional consequences of aberrant methylation. Identification of the factors regulating DNA methylation and demethylation may reveal novel targets for therapeutic intervention. Because DNA methylation does not alter the primary DNA sequence and is reversible, epigenetics-based therapeutics may be able to restore the activity of silenced tumor suppressors even in advanced tumours.

\section{Acknowledgments}

We thank LJ Rush, DJ Smiraglia, WA Held for helpful comments and honest criticism. We apologise to those authors whose work could not be cited due to restrictions in length of the review. This work was supported in part by grants P30 CA16058, R21 CA80912, RO1 GM58269, RO1 DE13123 (C Plass), and P30 CA 16056 and RO1 EY11279 (PD Soloway).

\section{References}

1 Ramsahoye BH, Biniszkiewicz D, Lyko F, Clark V, Bird AP, Jaenisch R: Non-CpG methylation is prevalent in embryonic stem cells and may be mediated by DNA methyltransferase 3a [In Process Citation]. Proc Natl Acad Sci USA 2000; 97: 5237 5242.

2 Vertino PM, Yen RW, Gao J, Baylin SB: De novo methylation of CpG island sequences in human fibroblasts overexpressing DNA (cytosine-5-)-methyltransferase. Mol Cell Biol 1996; 16: $4555-4565$

3 Li E, Bestor TH, Jaenisch R: Targeted mutation of the DNA methyltransferase gene results in embryonic lethality. Cell 1992; 69: 915-926.

4 Okano M, Bell DW, Haber DA, Li E: DNA methyltransferases Dnmt3a and Dnmt3b are essential for de novo methylation and mammalian development. Cell 1999; 99: 247-257.

5 Fuks F, Burgers WA, Godin N, Kasai M, Kouzarides T: Dnmt3a binds deacetylases and is recruited by a sequence-specific repressor to silence transcription. EMBO J 2001; 20: 25362544 
6 Robertson KD, Uzvolgyi E, Liang $\mathrm{G}$ et al: The human DNA methyltransferases (DNMTs) 1, 3a and 3b: coordinate mRNA expression in normal tissues and overexpression in tumors. Nucleic Acids Res 1999; 27: 2291-2298.

7 Howell CY, Bestor TH, Ding F et al: Genomic imprinting disrupted by a maternal effect mutation in the Dnmt1 gene. Cell 2001; 104: 829-838.

8 Oswald J, Engemann S, Lane $\mathrm{N}$ et al: Active demethylation of the paternal genome in the mouse zygote [In Process Citation]. Curr Biol 2000; 10: 475 - 478 .

9 Tamaru H, Selker EU: A histone H3 methyltransferase controls DNA methylation in Neurospora crassa. Nature 2001; 414: $277-283$.

10 Robertson KD, Ait-Si-Ali S, Yokochi T, Wade PA, Jones PL, Wolffe AP: DNMT1 forms a complex with Rb, E2F1 and HDAC1 and represses transcription from E2F-responsive promoters. Nat Genet 2000; 25: 338-342.

11 Tatematsu KI, Yamazaki T, Ishikawa F: MBD2-MBD3 complex binds to hemi-methylated DNA and forms a complex containing DNMT1 at the replication foci in late S phase. Genes Cells 2000; 5: 677-688.

12 Wutz A, Smrzka OW, Schweifer N, Schellander K, Wagner EF, Barlow DP: Imprinted expression of the Igf2r gene depends on an intronic CpG island [see comments]. Nature 1997; 389: $745-749$.

13 Birger Y, Shemer R, Perk J, Razin A: The imprinting box of the mouse Igf2r gene. Nature 1999; 397: 84-88.

14 Plass C, Shibata H, Kalcheva I et al: Identification of Grf1 on mouse chromosome 9 as an imprinted gene by RLGS-M. Nat Genet 1996; 14: 106-109.

15 Yoon B-J, Herman H, Sikora A: Regulation of DNA methylation of Rasgrf1. Nature Genet 2002; 30: 92-96.

16 Yates PA, Burman RW, Mummaneni P, Krussel S, Turker MS: Tandem B1 elements located in a mouse methylation center provide a target for de novo DNA methylation. J Biol Chem 1999; 274: 36357-36361.

17 Luff B, Pawlowski L, Bender J: An inverted repeat triggers cytosine methylation of identical sequences in Arabidopsis. Mol Cell 1999; 3: 505-511.

18 Thorvaldsen JL, Duran KL, Bartolomei MS: Deletion of the H19 differentially methylated domain results in loss of imprinted expression of H19 and Igf2. Genes Dev 1998; 12: 3693 - 3702.

19 Bourc'his D, Xu GL, Lin CS, Bollman B, Bestor TH: Dnmt3L and the Establishment of Maternal Genomic Imprints. Science 2001; 22: 22.

20 Pelissier T, Wassenegger M: A DNA target of $30 \mathrm{bp}$ is sufficient for RNA-directed DNA methylation. Rna 2000; 6: 55-65.

21 Cogoni C, Irelan JT, Schumacher M, Schmidhauser TJ, Selker EU, Macino G: Transgene silencing of the al-1 gene in vegetative cells of Neurospora is mediated by a cytoplasmic effector and does not depend on DNA-DNA interactions or DNA methylation. EMBO J 1996; 15: $3153-3163$.

22 Selker EU: Gene silencing: repeats that count. Cell 1999; 97: $157-160$

23 Watt F, Molloy PL: Cytosine methylation prevents binding to DNA of a HeLa cell transcription factor required for optimal expression of the adenovirus major late promoter. Genes Dev 1988; 2: 1136-1143.

24 Kovesdi I, Reichel R, Nevins JR: Role of an adenovirus E2 promoter binding factor in E1A-mediated coordinate gene control. Proc Natl Acad Sci USA 1987; 84: 2180-2184.

25 Lewis JD, Meehan RR, Henzel WJ et al: Purification, sequence, and cellular localization of a novel chromosomal protein that binds to methylated DNA. Cell 1992; 69: 905 -914.

26 Meehan RR, Lewis JD, McKay S, Kleiner EL, Bird AP: Identification of a mammalian protein that binds specifically to DNA containing methylated CpGs. Cell 1989; 58: 499-507.
27 Nan X, Ng HH, Johnson CA et al: Transcriptional repression by the methyl-CpG-binding protein MeCP2 involves a histone deacetylase complex [see comments]. Nature 1998; 393: 386 389.

28 Amir RE, Van den Veyver IB, Wan M, Tran CQ, Francke U, Zoghbi HY: Rett syndrome is caused by mutations in X-linked MECP2, encoding methyl-CpG-binding protein 2. Nat Genet 1999; 23: $185-188$.

29 Hendrich B, Bird A: Identification and characterization of a family of mammalian methyl-CpG binding proteins. Mol Cell Biol 1998; 18: 6538-6547.

$30 \mathrm{Ng} \mathrm{HH}$, Zhang Y, Hendrich B et al: MBD2 is a transcriptional repressor belonging to the MeCP1 histone deacetylase complex. Nat Genet 1999; 23: 58-61.

31 Laherty CD, Yang WM, Sun JM, Davie JR, Seto E, Eisenman RN: Histone deacetylases associated with the mSin3 corepressor mediate mad transcriptional repression. Cell 1997; 89: 349 356.

32 Nagy L, Kao HY, Chakravarti D et al: Nuclear receptor repression mediated by a complex containing SMRT, mSin3A, and histone deacetylase. Cell 1997; 89: 373 - 380.

33 Zhang Y, Ng HH, Erdjument-Bromage H, Tempst P, Bird A, Reinberg D: Analysis of the NuRD subunits reveals a histone deacetylase core complex and a connection with DNA methylation. Genes Dev 1999; 13: 1924-1935.

34 Gibbons RJ, McDowell TL, Raman S et al: Mutations in ATRX, encoding a SWI/SNF-like protein, cause diverse changes in the pattern of DNA methylation. Nat Genet 2000; 24: 368-371.

35 Knoepfler PS, Eisenman RN: Sin meets NuRD and other tails of repression. Cell 1999; 99: 447-450.

36 Kuo MH, Allis CD. Roles of histone acetyltransferases and deacetylases in gene regulation. Bioessays 1998; 20: 615-626.

37 Guschin D, Wade PA, Kikyo N, Wolffe AP: ATP-Dependent histone octamer mobilization and histone deacetylation mediated by the Mi-2 chromatin remodeling complex. Biochemistry 2000; 39: 5238-5245.

38 Tyler JK, Kadonaga JT. The 'dark side' of chromatin remodeling: repressive effects on transcription. Cell 1999; 99: 443446.

39 Selker EU: Trichostatin A causes selective loss of DNA methylation in Neurospora. Proc Natl Acad Sci USA 1998; 95: 9430-9435.

40 Rountree MR, Bachman KE, Baylin SB: DNMT1 binds HDAC2 and a new co-repressor, DMAP1, to form a complex at replication foci. Nat Genet 2000; 25: 269-277.

41 Fuks F, Burgers WA, Brehm A, Hughes-Davies L, Kouzarides T: DNA methyltransferase Dnmt 1 associates with histone deacetylase activity. Nat Genet 2000; 24: 88-91.

42 Hark AT, Schoenherr CJ, Katz DJ, Ingram RS, Levorse JM, Tilghman SM: CTCF mediates methylation-sensitive enhancer-blocking activity at the H19/Igf2 locus [see comments]. Nature 2000; 405: 486-489.

43 Bell AC, Felsenfeld G: Methylation of a CTCF-dependent boundary controls imprinted expression of the Igf 2 gene [see comments]. Nature 2000; 405: 482-485.

44 Lutz M, Burke LJ, Barreto G et al: Transcriptional repression by the insulator protein CTCF involves histone deacetylases. Nucleic Acids Res 2000; 28: 1707-1713.

45 Zacharias W: Methylation of cytosine influences the DNA structure. Exs 1993; 64: 27 - 38.

46 Gruenbaum Y, Cedar H, Razin A: Substrate and sequence specificity of a eukaryotic DNA methylase. Nature 1982; 295 : $620-622$.

47 Zacharias W, Caserta M, O'Connor TR, Larson JE, Wells RD: Cytosine methylation as an effector of right-handed to lefthanded DNA structural transitions. Gene 1988; 74: 221-224. 
48 Jackson-Grusby L, Beard C, Possemato R et al: Loss of genomic methylation causes p53-dependent apoptosis and epigenetic deregulation [In Process Citation]. Nat Genet 2001; 27: 31 - 39

49 Antequera F, Bird A: Number of CpG islands and genes in human and mouse. Proc Natl Acad Sci USA 1993; 90: 11995 11999.

50 Bartolomei MS, Tilghman SM: Genomic imprinting in mammals. Annu Rev Genet 1997; 31: 493-525.

51 Feil R, Khosla S: Genomic imprinting in mammals: an interplay between chromatin and DNA methylation? Trends Genet 1999; 15: $431-435$.

52 Pfeifer K: Mechanisms of genomic imprinting. Am J Hum Genet 2000; 67: 777-787.

53 Reik W, Walter J. Genomic imprinting: parental influence on the genome. Nat Rev Genet 2001; 2: $21-32$.

54 Stoger R, Kubicka P, Liu CG et alMaternal-specific methylation of the imprinted mouse Igf2r locus identifies the expressed locus as carrying the imprinting signal. Cell 1993; 73: 61-71.

55 Bartolomei MS, Webber AL, Brunkow ME, Tilghman SM: Epigenetic mechanisms underlying the imprinting of the mouse H19 gene. Genes Dev 1993; 7: 1663 - 1673.

56 Mann JR, Szabo PE, Reed MR, Singer-Sam J: Methylated DNA sequences in genomic imprinting. Crit Rev Eukaryot Gene Expr 2000; 10: $241-257$

$57 \mathrm{Li} \mathrm{E}$, Beard C, Jaenisch R: Role for DNA methylation in genomic imprinting [see comments]. Nature 1993; 366: 362-365.

58 Kanduri C, Pant V, Loukinov D et al: Functional association of CTCF with the insulator upstream of the H19 gene is parent of origin-specific and methylation-sensitive. Curr Biol 2000; 10 $853-856$.

59 Simon I, Tenzen T, Reubinoff BE, Hillman D, McCarrey JR, Cedar H: Asynchronous replication of imprinted genes is established in the gametes and maintained during development. Nature 1999; 401: 929-932.

60 Feil R, Boyano MD, Allen ND, Kelsey G: Parental chromosomespecific chromatin conformation in the imprinted U2af1-rs1 gene in the mouse. J Biol Chem 1997; 272: 20893 - 20900.

61 Shibata H, Yoshino K, Sunahara S et al: Inactive allele-specific methylation and chromatin structure of the imprinted gene U2af1-rs1 on mouse chromosome 11. Genomics 1996; 35: 248 252.

62 Jones PA, Laird PW: Cancer epigenetics comes of age. Nat Genet 1999; 21: $163-167$.

63 Baylin SB, Herman JG: DNA hypermethylation in tumorigenesis: epigenetics joins genetics [In Process Citation]. Trends Genet 2000; 16: 168-174.

64 Costello JF, Plass C: Methylation matters. J Med Genet 2001; 38: $285-303$

65 Ehrlich M, Gama-Sosa MA, Huang LH et al: Amount and distribution of 5-methylcytosine in human DNA from different types of tissues of cells. Nucleic Acids Res 1982; 10: 2709-2721.

66 Gama-Sosa MA, Wang RY, Kuo KC, Gehrke CW, Ehrlich M: The 5 -methylcytosine content of highly repeated sequences in human DNA. Nucleic Acids Res 1983; 11: 3087 - 3095.

67 Cravo M, Pinto R, Fidalgo P et al: Global DNA hypomethylation occurs in the early stages of intestinal type gastric carcinoma. Gut 1996; 39: 434-438.

68 Kim YI, Giuliano A, Hatch KD et al: Global DNA hypomethylation increases progressively in cervical dysplasia and carcinoma. Cancer 1994; 74: 893-899.

69 Soares J, Pinto AE, Cunha CV et al: Global DNA hypomethylation in breast carcinoma: correlation with prognostic factors and tumor progression. Cancer 1999; 85: 112-118.

70 Clark SJ, Harrison J, Paul CL, Frommer M: High sensitivity mapping of methylated cytosines. Nucleic Acids Res 1994; 22 2990-2997.
71 Herman JG, Graff JR, Myohanen S, Nelkin BD, Baylin SB: Methylation-specific PCR: a novel PCR assay for methylation status of CpG islands. Proc Natl Acad Sci U S A 1996; 93: 9821 9826.

72 Gonzalgo ML, Jones PA: Rapid quantitation of methylation differences at specific sites using methylation-sensitive single nucleotide primer extension (Ms-SNuPE). Nucleic Acids Res 1997; 25: 2529-2531.

73 Huang TH, Perry MR, Laux DE: Methylation profiling of CpG islands in human breast cancer cells. Hum Mol Genet 1999; 8: $459-470$.

74 Yan PS, Perry MR, Laux DE, Asare AL, Caldwell CW, Huang TH: CpG island arrays: an application toward deciphering epigenetic signatures of breast cancer. Clin Cancer Res 2000; 6: $1432-1438$

75 Costello JF, Fruhwald MC, Smiraglia DJ et al: Aberrant CpGisland methylation has non-random and tumour-type-specific patterns [see comments]. Nat Genet 2000; 24: 132-138.

76 Fruhwald MC, O’Dorisio MS, Dai Z et al: Aberrant hypermethylation of the major breakpoint cluster region in $17 \mathrm{p} 11.2$ in medulloblastomas but not supratentorial PNETs. Genes Chromosomes Cancer 2001; 30: 38-47.

77 Rush LJ, Dai Z, Smiraglia DJ, Gao X et al: Novel methylation targets in de novo acute myeloid leukemia with prevalence of chromosome 11 loci. Blood 2001; 97: 3226-3233.

78 Smiraglia DJ, Rush LJ, Fruhwald MC et alExcessive CpG island hypermethylation in cancer cell lines versus primary human malignancies. Hum Mol Genet 2001; 10: 1413-1419.

79 Dai Z, Lakshmanan RR, Zhu W-G et al: Global methylation profiling of lung cancer identifies novel methylated genes. Neoplasia 2001; 3: 314-323.

80 Nagai H, Ponglikitmongkol M, Mita E et al: Aberration of genomic DNA in association with human hepatocellular carcinomas detected by 2-dimensional gel analysis. Cancer Res 1994; 54: $1545-1550$.

81 Yoshikawa H, Matsubara K, Qian GS et al: SOCS-1, a negative regulator of the JAK/STAT pathway, is silenced by methylation in human hepatocellular carcinoma and shows growthsuppression activity. Nat Genet 2001; 28: 29-35.

82 Dammann R, Li C, Yoon JH, Chin PL, Bates S, Pfeifer GP: Epigenetic inactivation of a RAS association domain family protein from the lung tumour suppressor locus $3 \mathrm{p} 21.3$. Nat Genet 2000; 25: 315-319.

83 Dreijerink K, Braga E, Kuzmin I et al: The candidate tumor suppressor gene, RASSF1A, from human chromosome $3 \mathrm{p} 21.3$ is involved in kidney tumorigenesis. Proc Natl Acad Sci USA 2001; 98: $7504-7509$.

84 Agathanggelou A, Honorio S, Macartney DP et al: Methylation associated inactivation of RASSF1A from region $3 \mathrm{p} 21.3$ in lung, breast and ovarian tumours. Oncogene 2001; 20: 15091518.

85 Fruhwald MC, O'Dorisio MS, Dai Z et al: Aberrant promoter methylation of previously unidentified target genes is a common abnormality in medulloblastomas-implications for tumor biology and potential clinical utility. Oncogene 2001; 20: $5033-5042$

86 Plass C, Yu F, Yu L et al: Restriction landmark genome scanning for aberrant methylation in primary refractory and relapsed acute myeloid leukemia; involvement of the WIT-1 gene. Oncogene 1999; 18: 3159-3165.

87 Rainier S, Johnson LA, Dobry CJ, Ping AJ, Grundy PE and Feinberg AP. Relaxation of imprinted genes in human cancer. Nature 1993; 362: $747-749$.

88 Ogawa O, Eccles MR, Szeto J et al: Relaxation of insulin-like growth factor II gene imprinting implicated in Wilms' tumour. Nature 1993; 362: $749-751$. 
89 Moulton T, Crenshaw T, Hao Y et al: Epigenetic lesions at the H19 locus in Wilms' tumour patients. Nat Genet 1994; 7: $440-$ 447.

90 Steenman MJ, Rainier S, Dobry CJ, Grundy P, Horon IL, Feinberg AP: Loss of imprinting of IGF2 is linked to reduced expression and abnormal methylation of H19 in Wilms' tumour [published erratum appears in Nat Genet 1994 Oct;8(2):203]. Nat Genet 1994; 7: $433-439$.

91 Taniguchi T, Sullivan MJ, Ogawa O, Reeve AE: Epigenetic changes encompassing the IGF2/H19 locus associated with relaxation of IGF2 imprinting and silencing of H19 in Wilms tumor. Proc Natl Acad Sci USA 1995; 92: 2159-2163.

92 Rainier S, Dobry CJ, Feinberg AP: Loss of imprinting in hepatoblastoma. Cancer Res 1995; 55: 1836-1838.

$93 \mathrm{Vu}$ TH, Yballe C, Boonyanit S, Hoffman AR: Insulin-like growth factor II in uterine smooth-muscle tumors: maintenance of genomic imprinting in leiomyomata and loss of imprinting in leiomyosarcomata. J Clin Endocrinol Metab 1995; 80: 16701676.

94 Douc-Rasy S, Barrois M, Fogel S et al: High incidence of loss of heterozygosity and abnormal imprinting of H19 and IGF2 genes in invasive cervical carcinomas. Uncoupling of H19 and IGF2 expression and biallelic hypomethylation of H19. Oncogene 1996; 12: $423-430$.

95 Oda $\mathrm{H}$, Kume $\mathrm{H}$, Shimizu $\mathrm{Y}$, Inoue $\mathrm{T}$, Ishikawa $\mathrm{T}$. Loss of imprinting of igf2 in renal-cell carcinomas. Int J Cancer 1998; 75: $343-346$.

96 Pedone PV, Tirabosco R, Cavazzana AO et al: Mono- and biallelic expression of insulin-like growth factor II gene in human muscle tumors. Hum Mol Genet 1994; 3: 1117-1121.

97 Zhan S, Shapiro DN, Helman LJ: Activation of an imprinted allele of the insulin-like growth factor II gene implicated in rhabdomyosarcoma. J Clin Invest 1994; 94: 445 - 448.

98 Uyeno S, Aoki Y, Nata M et al: IGF2 but not H19 shows loss of imprinting in human glioma. Cancer Res 1996; 56: 5356-5359.

99 Cui H, Horon IL, Ohlsson R, Hamilton SR, Feinberg AP: Loss of imprinting in normal tissue of colorectal cancer patients with microsatellite instability. Nat Med 1998; 4: 1276-1280.

100 Takano Y, Shiota G, Kawasaki H: Analysis of genomic imprinting of insulin-like growth factor 2 in colorectal cancer. Oncology 2000; 59: 210-216.

101 Weksberg R, Shen DR, Fei YL, Song QL, Squire J: Disruption of insulin-like growth factor 2 imprinting in Beckwith-Wiedemann syndrome. Nat Genet 1993; 5: $143-150$.

102 Ohlsson R, Nystrom A, Pfeifer-Ohlsson S et al: IGF2 is parentally imprinted during human embryogenesis and in the Beckwith-Wiedemann syndrome. Nat Genet 1993; 4: $94-$ 97.

103 Mannens M, Hoovers JM, Redeker E et al: Parental imprinting of human chromosome region 11p15.3-pter involved in the Beckwith-Wiedemann syndrome and various human neoplasia. Eur J Hum Genet 1994; 2: 3-23.

104 Nakagawa H, Chadwick RB, Peltomaki P, Plass C, Nakamura Y, de La Chapelle A: Loss of imprinting of the insulin-like growth factor II gene occurs by biallelic methylation in a core region of H19-associated CTCF-binding sites in colorectal cancer. Proc Natl Acad Sci USA 2001; 98: 591-596.

105 Takai D, Gonzales FA, Tsai YC, Thayer MJ, Jones PA. Large scale mapping of methylcytosines in CTCF-binding sites in the human H19 promoter and aberrant hypomethylation in human bladder cancer. Hum Mol Genet 2001; 10: 2619-2626.
106 Caron H, Peter M, van Sluis P et al: Evidence for two tumour suppressor loci on chromosomal bands 1p35-36 involved in neuroblastoma: one probably imprinted, another associated with N-myc amplification. Hum Mol Genet 1995; 4: 535-539.

107 Kaghad M, Bonnet H, Yang A et al: Monoallelically expressed gene related to p53 at $1 \mathrm{p} 36$, a region frequently deleted in neuroblastoma and other human cancers. Cell 1997; 90: 809 _ 819.

108 Corn PG, Kuerbitz SJ, van Noesel MM et al: Transcriptional silencing of the p73 gene in acute lymphoblastic leukemia and Burkitt's lymphoma is associated with 5' CpG island methylation. Cancer Res 1999; 59: 3352-3356.

109 Banelli B, Casciano I, Romani M. Methylation-independent silencing of the p73 gene in neuroblastoma. Oncogene 2000; 19: $4553-4556$.

110 Matsuoka S, Thompson JS, Edwards MC et al: Imprinting of the gene encoding a human cyclin-dependent kinase inhibitor, p57KIP2, on chromosome 11p15. Proc Natl Acad Sci USA 1996; 93: $3026-3030$.

111 Kondo M, Matsuoka S, Uchida K et al: Selective maternal-allele loss in human lung cancers of the maternally expressed p57KIP2 gene at 11p15.5. Oncogene 1996; 12: 1365 - 1368.

112 Thompson JS, Reese KJ, DeBaun MR, Perlman EJ, Feinberg AP: Reduced expression of the cyclin-dependent kinase inhibitor gene p57KIP2 in Wilms' tumor. Cancer Res 1996; 56: $5723-$ 5727.

$113 \mathrm{Yu}$ Y, Xu F, Peng H et al: NOEY2 (ARHI), an imprinted putative tumor suppressor gene in ovarian and breast carcinomas. Proc Natl Acad Sci USA 1999; 96: 214-219.

114 Schwienbacher C, Gramantieri L, Scelfo R et al: Gain of imprinting at chromosome 11p15: A pathogenetic mechanism identified in human hepatocarcinomas. Proc Natl Acad Sci USA 2000; 97: 5445-5449.

115 Baylin SB, Herman JG, Graff JR, Vertino PM, Issa JP: Alterations in DNA methylation: a fundamental aspect of neoplasia. $A d v$ Cancer Res 1998; 72: 141-196.

116 Eads CA, Danenberg KD, Kawakami K, Saltz LB, Danenberg PV, Laird PW: CpG island hypermethylation in human colorectal tumors is not associated with DNA methyltransferase overexpression. Cancer Res 1999; 59: 2302-2306.

117 Nass SJ, Ferguson AT, El-Ashry D, Nelson WG, Davidson NE. Expression of DNA methyl-transferase (DMT) and the cell cycle in human breast cancer cells. Oncogene 1999; 18: 7453-7461.

118 Belinsky SA, Nikula KJ, Baylin SB, Issa JP: Increased cytosine DNA-methyltransferase activity is target-cell-specific and an early event in lung cancer. Proc Natl Acad Sci USA 1996; 93 : 4045 - 4050.

119 Laird PW, Jackson-Grusby L, Fazeli A et al: Suppression of intestinal neoplasia by DNA hypomethylation. Cell 1995; 81: $197-205$.

$120 \mathrm{Wu}$ J, Issa JP, Herman J, Bassett Jr DE, Nelkin BD, Baylin SB: Expression of an exogenous eukaryotic DNA methyltransferase gene induces transformation of NIH 3T3 cells. Proc Natl Acad Sci USA 1993; 90: 8891-8895.

121 Esteller M, Garcia-Foncillas J, Andion E et al: Inactivation of the DNA-repair gene MGMT and the clinical response of gliomas to alkylating agents. N Engl J Med 2000; 343: 13501354.

122 Palmisano WA, Divine KK, Saccomanno G et al: Predicting lung cancer by detecting aberrant promoter methylation in sputum. Cancer Res 2000; 60: 5954-5958. 